\title{
IMPLEMENTASI CBR DALAM PENENTUAN OBAT YANG TEPAT BAGI PASIEN (STUDI KASUS RESEP ISPA)
}

\author{
Ahmad Cucus ${ }^{11}$ \\ Program Studi Teknik Informatika \\ Fakultas Ilmu Komputer \\ Universitas Bandar Lampung \\ E-mail: cucus_ahmad(ayahoo.com" \\ Handphone: $085658991557^{11}$
}

Jn. Z.A. Pagar Alam No.26 Labuhan Ratu Bandar Lampung 35142

Telp. (0721) 701463, (0721) 701979 Fax. (0721) 701467 Web. www ubl.ac id

\begin{abstract}
Abstrak
Berdasarkan penelitian yang di lakukan oleh Martin Khor pada tahum 2005, Data tentang tren dalam penggunaan obat -obatan menunjukkan bahwa rata-rata jumlah obat yang digunakan meningkat 1990-2003 2,2-2,7 per pasien. Hanya 40-50\% dari pasien diperlakukan sesuai dengan pedioman pengobatan siandar.

Hasil Survei Keschatan Fumah Tangga ditahun 1986 menumjukkan 42,2\% bayi dan $40,6 \%$ balita yang sakit disebabkan ISPA. Data Puskesmas (1986) menunjukkan bahwa 5 1.0\% bayi dan 43.1\% balita pengunjung puskesmas menderila ISPA. Pada SKRT 1992 ditemukan bahwa proporsi kematian bayi akibat ISPA adalah $36,0 \%$ di galongan umur 14 tahum adalah $13,0 \%$ yang sedangkan pada kelompok umur balita berkisar 2,3\% sebagian besar disebabkan oleh pneumania. Untuk membantu memurunkan angka kematian balita karena pneumonia, Sub. Dit. P2ISPA Dit. Jen. PPMPL.P telah membuat Buku Pedoman Pemberantasan Penyakit ISPA. Dalam buku tersebut, telah bahwa disebutkan salah satu tujuan progran ISPA yaitu memurunkan penggunaan antibiotik dan obat batuk yang kunang tepat pada pengobatan pemyakit ISPA (Enny Muchlastriningsih SKM).

Dengan menggunakan Computing Approach Case-Basedd Reasoning (CBR) yang dikombinasikan dengan Algoritma Pembelajaran Mesin (Mechine Leaming Algorifm) Nearest Neighbor (NN) sebagai metodologi jang diterapkan pada sebuah sistem pemunjang keputusan, diharapkan mampu uniuk membantu mengurangi angka kesalahan dalam pemberian abat dan resep pada pasien.
\end{abstract}

Kata Kunci : Case-Basedd Reasoning, Nearest Neighbor, ISPA, Algoritma Klasifikasi, AI, Sistem Penunjang Keputusan.

\section{PENDAhuluan}

Pengobatan yang tidak tepat, tidak efektif dan ekonomis, tidak efisiennya penggunaan obat obat umumnya diamati dalam sistem perawatan kesehatan $\mathrm{di}$ seluruh dunia, terutama di negara-negara berkembang. Namum, berbagai bentuk rescp yastg tidak tepat sering tidak diketahui oleh orang-orang yang tetibat dalam pengambilan keputusan pada sektor keschatan atau pelayanan keschatan.

Penggunaan obat yang tidak sesuai aturan hanya akan merugikan pasien Ironisnya, pasien sering tidak menyadarinya Pola pengobatan yang tidak rasional (Irrational Use of Drug atau IRUD) semakin banyak terjadi Bentuknya bisa berupa polifarmasi berupa pemberian beberapa obat sekaligus yang tidak perlu maupun pemberian antibiotik dan steroid yang berlebihan, mengutamakan obat nongenerik untuk mengambil keuntungan, juga obat-obatam yang pernakaiannya di luar indikasi resmi (off label use), (Dr. Ambrose (sah,).

Hal diatas berakibat fatal seperti yang penelitian yang di lakukan oleh Martin Khor pada tahun 2005, Data tentang tren dalam penggunaan obat -obatan menunjukkan bahwa rata-rata jumlah obat yang digunakan meningkat 1990-2003 2,2-2,7 per pasien. 
Hanya $40-50 \%$ dari pasien diperlakukan sesuai dengan pedoman pengobatan standar.

Dari 4.7 juta kasas baru hepatitis B dan C terdapat 2.3 juta yang mengalami pengobatan yang tidak standar, terjadi 160000 kasns baru HIV per tahun yang disebabkan oleh 15 miliar injeksi per tahun.

Sedangkan $4 \%$ sampai $10 \%$ dari pasien rawat inap nuah sakit menderita reaksi obat yang merugikan di negara maju. Hal Ini adalah yang keempat dari enam penyebab utama kenatian di. Ada peningkatan anti-mikroba, dengan perlawanan hingga 70 hingga $90 \%$ untuk asli antibiotik, lini pertama untuk disentri (shigella), pneumonia (pneumokokus) atau ISPA, gonore, dan infeksi rumah sakit (staph. Aureus).

Dari fenomena di atas, penyakit pneumonia merupakan penyakit yang sering melanda di Indonesia dan juga sering sekali terjadi kesalahan dalam pengobatan. Penyakit Infeksi Saluran Pernapasan Akut (ISPA) masih merupakan penyebab utama kesakitan dan kematian balita di indonesia yaitu sebesar $28 \%$. WHO memperkirakan kematian akibat pneumonia mencapai $10 \%-20 \%$ pertahun dari seluruh jumlah bila tidak diberi pengobatan. Kematian balita karena pneumoni secara nasional diperkirakan terdapat 6 per 1000 balita per tahun atau sekitar 150.000 balita pertahun. Salah satu sasaran pemberantasan penyakit ISPA pada balita adalah menurunkan angka kematian balita akibat pneumonia.

$\begin{array}{lrrr}\text { Hasil Survei Kesehatan } & \begin{array}{r}\text { Rumah } \\ \text { (selanjutnya }\end{array} & \text { Tangga } \\ \text { disingkat } & \text { SKRT) } & 1986\end{array}$ menunjukkan $42,2 \%$ bayi dan $40,6 \%$ balita yang sakit disebabkan ISPA. Data Puskesmas (1986) menunjukkan bahwa $51,0 \%$ bayi dan $43,1 \%$ balita pengunjung puskesmas menderita ISPA. Pada SKRT 1992 ditemukan bahwa proporsi kematian bayi akibat ISPA adalah $36,0 \%$ di golongan umur 14 tahun adalah $13,0 \%$ yang sedangkan pada kelompok umur balita berkisar $2,3 \%$ sebagian besar disebabkan oleh pneumonia. Untuk membantu menurunkan angka kematian balita karena pneumonia, Sub. Dit. P2ISPA Dit. Jen. PPMPLP telah memberat Buku Pedoman Pemberantasan Penyakit ISPA. Dalam boku tersebut, telah bahwa disebutkan salah satu tujuan program ISPA yaitu menurunkan penggunaan antibiotik dan obat batuk yang kurang tepat pada pengobatan penyakit ISPA (Enny Muchlastriningsih SKM).

Case Basedd Reasoning (CBR) atau yang sering kita dengar sebagai penalaran berbasis kasus memiliki sejarah yang relatif muda. Metode ini berasal dari penclitian dalam ilmu kognitif. Kontribusi paling awal dari penelitian ini berasal dari Roger Schank dan rekanrekannya di Yale University.

Selama periode 1977-1993, penelitian CBR dianggap sebagai model tingkat tinggi untuk pemrosesan kognitif. CBR berfokus pada masalah seperti bagaimana manusia mempelajari keterampilan baru dan bagaimana manusia menghasilkan hipotesis tentang situasi baru tersebut berdasarkan pada pengalaman masa lalu mereka. Tujuan kognitif ini berbasis penelitian untuk membangun sistem pendukung keputusan guna membantu orang belajar (Sankar K. Pal \& Simon S. K. Shiu, 2004).

CBR banyak dimanfaatkan untuk pengambilan keputusan pada dunia kedokteran, industri, bisnis, perekonomian, dan lainnya, karena CBR memungkinkan kita untuk bekerja pada pengalaman masa lalu tanpa pemahaman lengkap mekanisme yang mendasari dari penelitian yang akan dilakukan. Begitu halnya dengan penilitian ini, akan menerapkan metode CBR untuk untuk mengembangkan sistem keputusan dalam bidang obat obatan. Oleh karena itu diperlukan alat bantu untuk mengotomatisasi pengambilan keputusan dengan menggunakan aplikasi yang menerapkan metode CBR schingga pengambilan keputusan tersebut lebih efektif dan akurat, dan dapat di jadikan acuan bagi instansi kesehatan.

\subsection{Identifikasi Masalah}

Berdasarkan kenyataan yang telah di sebutkan sebelumnya, maka identifikasi masalah dari penelitian ini dapat di rumuskan sebagai berikut:

1. Diperlukan adanya sistem penunjang keputusan penentuan obat ISPA yang tepat bagi pasien, baik berupa rancangan dataBased, sistem, maupun softwarenya. 
2. Belum adanya kriteria yang dapat digunakan untuk menentukan obat ISPA, sehingga diperlukan sebagai standard pemilihan obat.

\subsection{Ruang Lingkup Masalah}

Mengingat akan keterbatasan waktu, dan biaya maka ruang lingkup penelitian ini dibatasi pada: Case Basedd Reasoning akan di terapkan dalam sistem penunjang keputusan yang akan menentukan obat-obatan untuk ISPA yang tepat bagi pasien sesuai dengan parameter yang di tentukan.

\subsection{Rumusan Masalah}

Penumusan masalah dalam penelitian ini adalah:

1. Bagaimana menyusun sistem penunjang keputusan berbasis case Basedd reasoning untuk menentukan obat ISPA yang sesuai atan tepat bagi pasien

2. Bagaimana menentukan kriteria yang digunakan untuk menentukan obat ISPA sebagai standard pemilihan obat.

\subsection{Tujuan Penelitian}

Tujuan Penelitian:

1. Mengadakan sistem penunjang keputusan untuk menentukan obat ISPA yang tepat bagi pasien dengan metode $\mathrm{CBR}$.

2. Mendapakkan kriteria kriteria yang digunakan unruk menentukan obat ISPA sebagai standard pemilihan obat.

\subsection{Manfaat Penelitian}

Manfast dari penelition ini dari beberapa segi yakni:

1. Memberikan manfaat praktis adalah hasil dari penelitian ini diharapkan bermanfaat bagi pasien maupun tenaga medis untuk menentukan obat ISPA yang tepat.

2. Memberikan Manfaat teoritis semoga dapat memberikan sumbangan bagi pengembangan teori pendidikan. Terutama dalam pengembangan software berbasis CBR

3. Diperolehnya informasi dengan evaluasi tinggi dengan kualitas perangkat lunak yang baik.

\section{2, LANDASAN TEORI}

\subsection{Sistem Pendukung Keputusan}

Sistem penunjang keputusan juga dikenal dengan istilah DSS (Dicision Support System), dapat di artikan sebuah usaha untuk mendapatkan solusi atau pemecahan masalah dari permasalahan yang di hadapi, pemecahan masalah mungkin banyak memuat keputusan. Keputusan merupakan rangkaian tindakan yang perlu diikuti dalam memecahkan maslah untuk menghindari atau mengurangi dampak negative atau untuk memanfaatkan kesempatan.. DSS menyediakan informasi pemechan masalah maupun kemampuan komunikasi dalam memecahkan masalah semi terstruktur.

Tahapan pengambilan keputusan menurut Herbert A. Simon, ahli Manajemen Pemegang Nobel dari Carnegie-Melton University yauut :

a. Kegiatan Intelijen, mengamati lingkungan mencari kondisi - kondisi yang perlu diperbaiki.

b. Kegiatan yang merancang, menemukan, mengemangkan dan menganalisa berbagai alternative tindakan yang mungkin.

c. Kegiatan Memilih, Memilih atu rangkaian tindakan tertentu dari berberapa yang tersedia

d. Kegiatan Menelaah, menilai pilihan pilihan yang lalu.

\subsection{Case-Basedd Reasoning}

Case-Basedd Reasoning (CBR) atau yang kita kenal dengun sistem penalaran berbasis kasus, bukanlah sebuah teknologi seperti halnya pemrograman Linear, jaringan saraf tiruan, aloritma genetik namun CBR adalah perpaduan antara model cognitif dan metode untuk membangun sebuah sistem pakar hal ini di ungkapan oleh Janet Kolodner di taun 1993, hal senada juga di ungkapkan oleh lan Watson dalam artikelnya bahwa CBR adalah sebuah metodologi bukan sebuah teknologi.

Case-Basedd reasoning (CBR) adalah teknik penyelesaian masalah berdasarkan knowledge pengalaman yang lalu. Aamodt dan Plaza (1994) menggambarkan tipe CBR sebagai 
suatu proses melingkar yang terdiri dari the four Res:

1. Retrieve. Mendapatkan kasus-kasus yang mirip dibandingkan dengan kumpulan kasus-kasus dimasa lalu.Dimulai dengan tahapan mengenali masalah dan berakhir ketika kasus yang ingin dicari solusinya telah ditemukan senupa dengan kasus yang telah ada. Tahapan yang ada pada retrieve ini antara lain :
a. Identifikasi Masalah
b. Mernulai Pencocokan
c. Menyeleksi

2. Reuse. Menggunakan kembali kasus-kasus yang ada dan dicoba untuk menyelesaikan suatu masalah sekarang. Reuse suatu kasus dalam konteks kasus baru terfokus pada dua aspek yaitu : perbedaan antara kasus yang ada dengan kasus yang baru dan bagian mana dari retrieve case yang dapat digunakan pada kasus yang baru. Ada dua cara yang digunakan untuk me-reuse kasus yang telah ada yaitu : reuse solusi dari kasus yang telah ada (transformatial reuse) atau reuse metode kasus yang ada.

3. Revise. Merubah dan mengadopsi solusi yang ditawarkan jika perlu. Terdapat dua tugas utama dari tahapan ini yaitu:

\section{a. Evaluasi Solusi.}

Evaluasi solusi adalalt bagaimana hasil yang didapatkan setelah membandingkan solusi dengan keadaan yang sebenamya. Hal ini biasanya tahapan diluar dari sistim CBR. Pada thap evaluasi ini sering memerlukan waktu yang panjang tergantung dari aplikasi apa yang sedang dikembangkan.

b. Memperbaiki Kesalahan.

Perbaikan suatu kasus meliputi pengenalan kesalahan dari solusi yang dibuat dan mengambil atau membuat penjelasan tentang kesalahan tersebut.

4. Retain. Tetap memakai solusi yang terakhir sebagai bagian dari kasus barı. Pada tahap ini terjadi suatu proses penggabungan dari solusi kasus yang baru yang benar ke knowledge yang telah ada. Terdapat tiga tahapan antara lain : extract. index dan integrat.

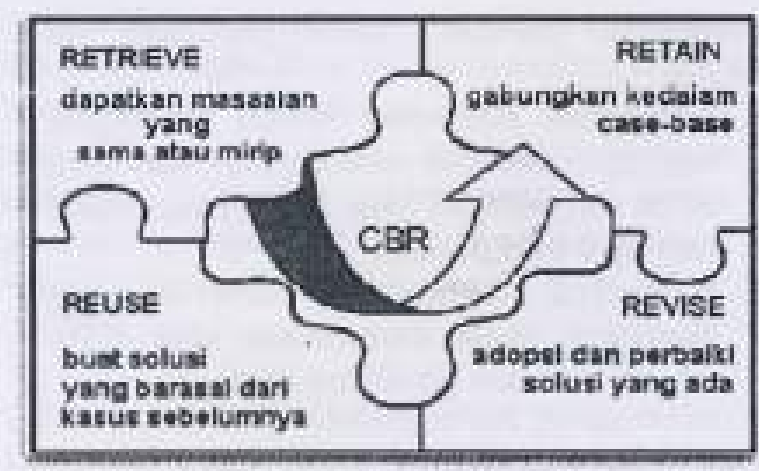

Gambar 1. Tahap CBR

\subsection{ISPA}

ISPA adalah infeksi saluran pernapasan yang berlangsung sampai 14 hari. Yang dimaksud dengan saluran pernapasan adalah organ mulai dari hidung sampai gelembung paru, beserta organ-organ disekitamya seperti : sinus, ruang telinga tengah dan selaput paru.

Sebagian besar dari infeksi saluran pernapasan hanya bersifat ringan seperti batuk pilek dan tidak memerlukan pengobatan dengan antibiotik, namun demikian anak akan menderita pneumoni bíla infeksi paru ini tidak diobati dengan antibiotik dapat mengakibat kematian.

ISPA dapat ditularkan melalui air ludah, darah, bersin, udara pernapasan yang mengandung kuman yang terhirup oleh orang sehat kesaluran pernapasannya. 
Tanda-tanda bahaya dapat dilihat berdasarkan tanda-tanda klinis dan tanda-tanda laboratoris.

\section{Tanda-tanda klinis:}

1. Pada sistem respiratorik adalah: tachypnea, napas tak teratur (apnea), retraksi dinding thorak, napas cuping hidung, cyanosis, suara napas lemah atau hilang, grunting expiratoir dan wheering.

2. Pada sistem cardial adalah: tachycardia, bradyeardiam, hypertensi, hypotensi dan cardiac arrest.

3. Pada sistem cerebral adalah : gelisah, mudah terangsang, sakit kepala, bingung. papil bendung, kejang dan coma.

4. Pada hal umum adalah : letih dan berkeringat banyak.

Tanda-tanda laboratories:

1. Hypoxemia.

2. Hypercapaia.

3. Acydosis

(metabolik dan atau respiratorik).

Tanda-tanda bahaya pada anak golongan umur 2 bulan sampai 5 tahun adalah: tidak bisa minum, kejang, kesadaran menurun, stridor dan gizi buruk, sedangkan tanda bahaya pada anak golongan umur kurang dari 2 bulan adalah: kurang bisa minum (kemampuan mimumnya menurun ampai kurang dari setengah volume yang biasa diminumnya). kejang, kesadaran menunun, stridor, Wheezing. demam dan dingin.

\section{Pengobatan:}

1. Pneumonia berat: diberikan antibiotik parenteral, oksigendan sebagainya.

2. Pneumonia: diberi obat antibiotik kotrimoksasol peroral. Bila penderita tidak mungkin diberi kotrimoksasol atau ternyata dengan pemberian kontrmoksasol keadaan penderita menetap, dapat dipakai obat antibiotik pengganti yaitu ampisilin, amoksisilin atau penisilin prokan.

3. Bukan pneumonia: tanpa pemberian obat antibiotik. Diberikan perawatan di numah, untuk batuk dapat digunakan obat batuk tradisional atau obat batuk lain yang tidak mengandung zat yang merugikan seperti kodein,dekstrometorfan dan, antihistamin
Bila demam diherikan obat penurun panas yaitu parasetamol. Penderita dengan gejala batuk pilek bila pada pemeriksaan tenggorokan didapat adanya bercak nanah (eksudat) disertai pembesaran kelenjar getah bening dileher, dianggap sebagai radang tenggorokan oleh kuman streptococcuss dan harus diberi antibiotik (penisilin) selama 10 hari.

\section{Kerangka Pemikiran}

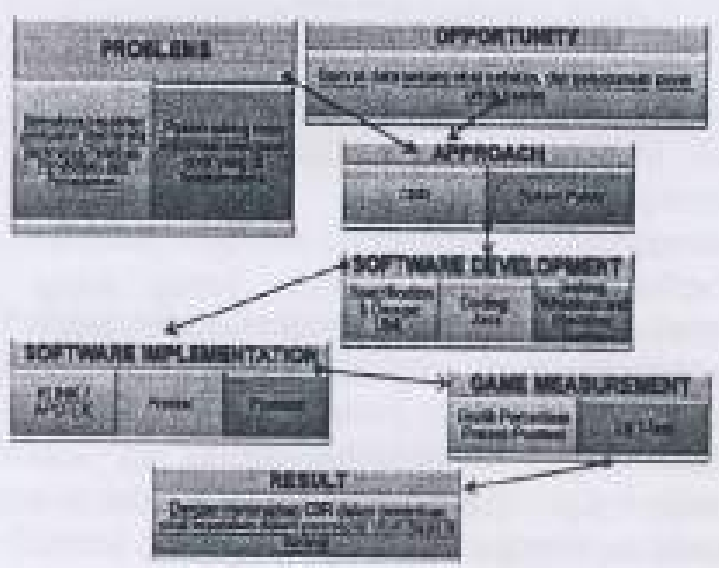

Gambar 2. Bagan Kerangka Pemiikanan

\section{METODE PENELITIAN}

\subsection{Perancangan Penelitian}

Dalam perancangan penelitian ini penulis akan membagi beberapa tugas yang akan di jadikan sebagai kerangka kerja, dimana kerangka kerja terseut akan menjadi acuan bagi penulis untuk menyelesaikan penelitian ini. Kerangka kerja tersebut akan digambarkan dalam sebuah diagram sebagai berikut: 


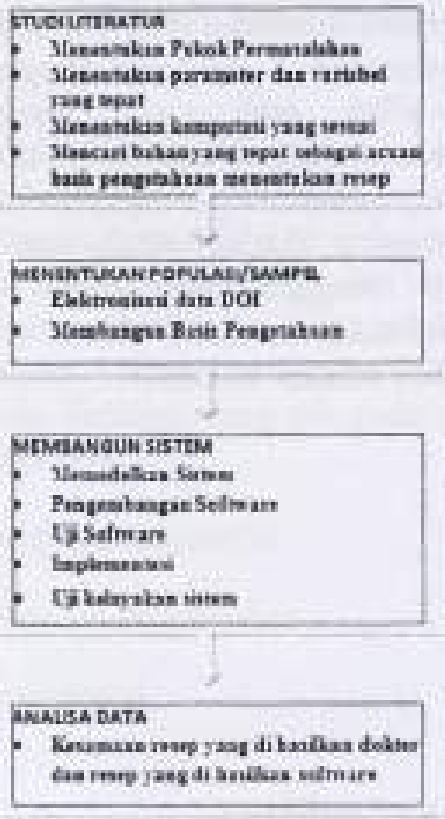

Gambar 3. Peranciungan Penelitian

Penelitian akan di lakukan dalam empat tahap, studi literatur, kemudian dilanjutkan dengan menetapkan populasi dan sampel, pembangunan sistem, serta analisa keberhasilan sistem tersebut. Setiap tahap dilakukan secara berurutan untuk lebih mendapatkan hasil yang lebih baik.

Selain langkah-langkah prosedural di atas penulis juga mengembangkan pendekatan penelitian, sebagai acuan agar penelitian sesuai dengan tujuan yang akan dicapai.

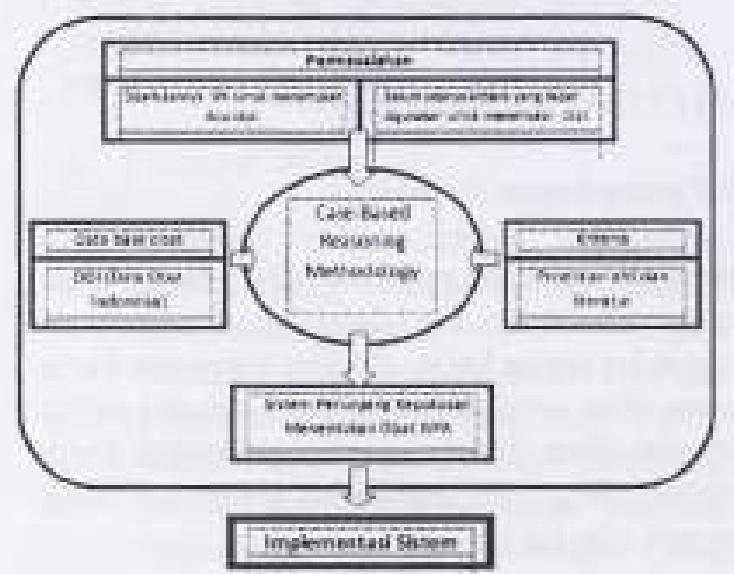

Gambar 4. Diagram Pendekakan Penellitan

\subsection{Jenis Penelitian}

Penelitian ini berjenis Experimental karena dilakukan dengan mengadakan manipulasi terhadap obyek penelitian serta diadakan kontrol terhadap variabel tertentu, Jika dilihat melalui hasilnya maka penelitian ini berjenis Applied Reseach (Penelitian Terapan) karena mempunyai alasan prakuis, keinginan untuk mengetahui, bertujuan agar dapat melakukan sesuatu yang lebih baik, efektif, efisien.

\subsection{Metode Pengumpulan Data}

Pengumpulan data dilakukan dengan beberapa cara, yaitu dengan studi literatur melalui media cetak dan elektronik, serta di lakukan wawancara dengan pakar untuk mendapatkan, dataBased yang berkaitan dengan Data Obat Indonesia.

\subsubsection{Data (Primer dan selunder)}

1. Primer

Data didapat dengan mencari sumber mengenai pengobatan ISPA, hal hal yang dapat mempengaruhinya sehingga akan di dapatkan kriteria apa saja yang di ambil para pakar dalam hal pengobatan ISPA

\section{Tabel I. Jenis ISPA}

\begin{tabular}{|c|c|c|}
\hline $\operatorname{man} \mid a n$ & Gritivens: & Gextitan \\
\hline \multirow{10}{*}{ 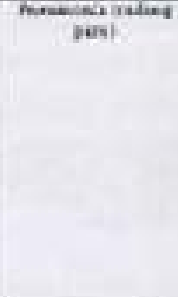 } & Melouldew & Alleatu \\
\hline & Ixpetals & tria tarat \\
\hline & mongel & 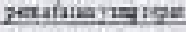 \\
\hline & imas & Amas ton itikei \\
\hline & 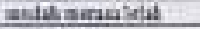 & mompere \\
\hline & Hencalat & \\
\hline & Irogkaruls & \\
\hline & arfin netulatrial & \\
\hline & Intcasolanh & \\
\hline & 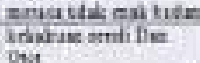 & \\
\hline
\end{tabular}

Tabel 2. Macan-macam Obat ISPA 


\begin{tabular}{|c|c|c|}
\hline \multicolumn{3}{|c|}{ 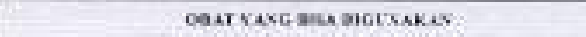 } \\
\hline ACrNCE & SiticoniLitx & Gesil: \\
\hline ANCA2ax & conesen & Casox \\
\hline 4 낮 & Shathrue & putatios \\
\hline AIsLak & 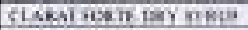 & fot 57 Troocts \\
\hline atchins & scacasboxint & 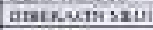 \\
\hline Cultor & CLWTKantT & Dincoxax \\
\hline CILIOKNONOU1 & ceswochtiv & 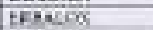 \\
\hline cins & Sisingox & yemose \\
\hline $\operatorname{cin} x+2 \operatorname{sex}$ & somiris & Hoxer \\
\hline 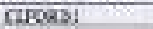 & CoRsace & Haxistit \\
\hline CIIXSO & cosisince & sitwootर \\
\hline 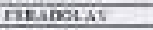 & croketrT & 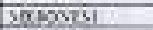 \\
\hline crmuli & $\cos \cos ^{-}$ & Lobon \\
\hline 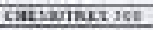 & $\operatorname{son} \frac{1}{2}$ & Dxsowal \\
\hline EYSASAT & Gosmux & scores \\
\hline Evingixs & 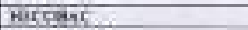 & Sthnox \\
\hline EVALTS & DCW Yis & Sienvail \\
\hline mos & momaus & xpes: \\
\hline Fate: & K, $100 \alpha$ & OXTLECD \\
\hline riccothas in: & 2uscors & puratioge \\
\hline moxen & (10)2 & excost \\
\hline Dopace & Inocis & knireues: \\
\hline 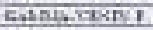 & inches & Dowace \\
\hline ThOND & Inokes LVus & merrox \\
\hline 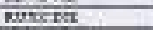 & उnowe & $00 \cos$ \\
\hline Coxpoce & IIS & gisot \\
\hline LWh & Mflewis & 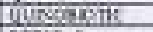 \\
\hline 50hacros & $200 \mathrm{Dx}$ & Buthas \\
\hline Seminvert & कextain & \\
\hline
\end{tabular}

2.

ekunder

Ekstraksi data obat di dapat dari buku Data Obat Indonesia, sebagai contoh beberapa bagian dari lembaran buku DOI yang datanya akan di ekstrak dan dimasukan kedalam dataBased obat

Tabel 3. Data Obat Indanesia

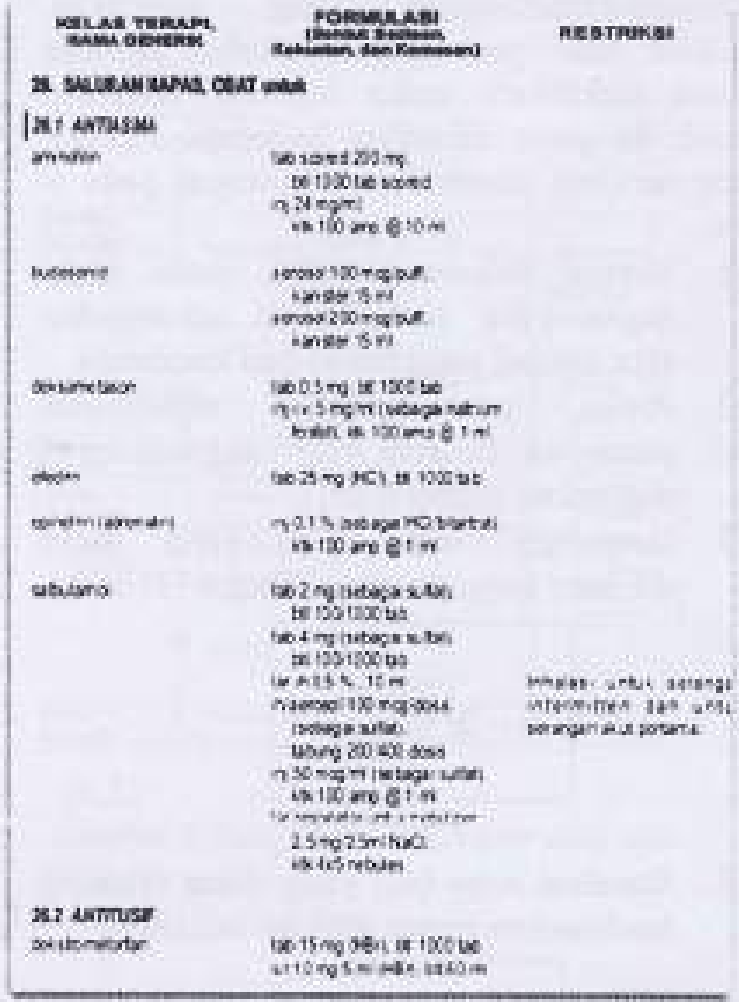

\subsubsection{Pengumpulan Data}

Pengumpulan data di lakukan dengan suty literatur maupun interview, namun penulis lebih banyak melakukan searching di situs situs yang berisi pengalaman pakar untuk pengbatan ISPA, juga data di dapatkan dengan elektronisasi Data Obat Indonesia yang terdapat dalam buku Data Obat Indonesia

\section{Metode Analisis Data dan Pengukuran}

\section{Penelitan}

Pada bagian ini akan dilakukan proses pernbandingan hasil pengukuran penelitian yang telah didapatkan sebelumnya. Adapun metode pembandingan ini adalah dengan analisa $T$-Test. Metode ini digunakan karena ttest dapat digunakan untuk menguji kecocokan atas perbedaan pada suatu eksperimen yang menggunakan satu kelompok sampel. Apabila sebelum melakukan eksperimen, peneliti melakukan pengukuran awal (pre test), maka peneliti akan mempunyai dua kelompok nilai yang berasal dari satu kelompok sampel. Apabila eksperimen itu mempunyai dampak terhadap hasil (ujuan eksperimen), maka kedua kelompok skor tersebut akan 
menunjukkanperbedaan yang signifikan. Apabila hasil perhitungan tersebut berbeda secara signifikan, maka hipotesa diterima Untuk itu perlu diketahui beberapa variabel yang menjadi parameter perhitungan pada ttest.

1. Derajat kebebasan (dk), yaitu suatu angka yang menjelaskan sekumpulan skor sampel yang bebas dari kesalahan.

2. Alpha, yaitu tingkat signifikansi pengujian. Besaran nilai yang umumnya digunakan adalah 0,05 .

3. Simpangan baku (Sd) yang dapat dihitung dengan numus sebagai berikut:

$$
\text { so }-\sqrt{\frac{\sum(x-x)^{2}}{n-1}}
$$

4. Standard error $(\mathrm{sx})$ yang dapat dihitung berdasarkan numus sebagai berikut

$$
5,=\frac{5 d}{\sqrt{n}}
$$

5. Sedangkan untuk nilai $t$, dapat dihirung dengan rumus berikut:

$$
t=\frac{x-\mu}{s}
$$

Dari hasil pethitungan tersebut, maka thitung akan dibandingkan dengan $t$ tabel. Jika perbedaannya signifikan, maka disimpulkan bahwa hipotesa diterima. Untuk perhitungan ini, dapat disederhanakan dengan menggunakan fungsi dari Microsoft Excel untuk Data Analysis, Microsoft Excel dapat digunakan untuk men-generate perhitungan $t$ test dengan lebih mudah dan cepat tanpa perlu melakukan perhitungan rumus secara detail dan manual.

\section{Tahapan Computing Approach dengan Studi Kasus Masalah Penelitian}

CBR memiliki empat tahapan umum yaitu.

\section{Retrieve}

Mendapatkan kasus-kasus mengenai penanganan penyakit ISPA yang dilakukan oleh pura pakur dan obat yang dihasilkan dari diagnosa tersebut kemudian mengenali masalah atau kasus baru yang timbul dan berakhir ketika kasus yang ingin dicari solusinya telah ditemukan serupa dengan kasus yang telah ada. Tahapan yang ada pada retrieve ini antara lain :

a. Identifikasi Masalah (Case

Representation)

Pengumumpulan parameter apa saja yang di jadikan para pakar untuk mengidentifikasi penyakit ISPA Setelah di lakukan study literatur maka didapatkan fenomens yang terjad: antar penyakit ispa, gejala gejala tersebut dapat kita cari yang sejenis dan kita jadikan kriteria yang termasuk dalam gejala gejala yang akan terjad: ketika seseorang terkena infeksi

\begin{tabular}{|c|c|c|}
\hline Jrain 1spd & Gejact Houm & Gejatain \\
\hline \multirow{12}{*}{$\begin{array}{l}\text { 7recmatia nenst } \\
\text { part }\end{array}$} & trakbenlatil & Eaftionbab \\
\hline & actidula & buikdarih \\
\hline & mastus & Porafaian velatepel \\
\hline & deman & 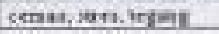 \\
\hline & methmenafelat. & D)eipmat \\
\hline & trakrafat & \\
\hline & aditherth & \\
\hline & vafm nababolkum & \\
\hline & 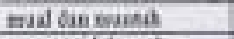 & \\
\hline & 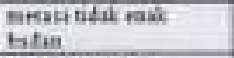 & \\
\hline & Detakiras ined & \\
\hline & 10blas ent & \\
\hline \multirow{9}{*}{$\begin{array}{l}\text { Nmianes. } \\
\text { Sertlotike! }\end{array}$} & betshterdadua & \\
\hline & Iriah & \\
\hline & E.eliata & \\
\hline & Gokrale & \\
\hline & 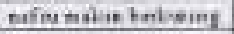 & \\
\hline & mal dar numb & \\
\hline & $\begin{array}{l}\text { mernatidin enal } \\
\text { badas }\end{array}$ & \\
\hline & Scialnafa & \\
\hline & bidkerasalhas:at & \\
\hline \multirow[t]{8}{*}{ 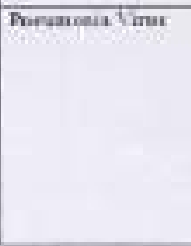 } & buth & honyententst \\
\hline & Itenlesula & maldeimutat \\
\hline & 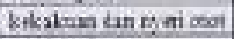 & kokakina ietdi \\
\hline & senkiatai & \\
\hline & Anawa & \\
\hline & menasel & \\
\hline & belmisyal & \\
\hline & What & \\
\hline
\end{tabular}
saluran pernafasan

Tabel 4. Daficar Penvakit ISPA

Dari tabel di atas kita bisa menarik parameter gejala apa saja yang bisa di derita oleh pasien yang terjangkit ISPA, seperti di bawah ini : 
Tabel 3. Kesimpulan Case Representarian

\begin{tabular}{|c|c|c|}
\hline Fodnkia & Eq+aws & Kormazil \\
\hline 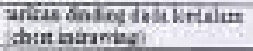 & Coolnas & (W. Tासा \\
\hline 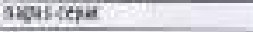 & trinin & Jaras:ala Sinz \\
\hline Umi & theje & Den fusma \\
\hline Bunk & Sera & 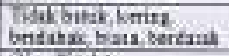 \\
\hline 108 & nechas & Qf. risk \\
\hline SALTHE: & Eirg & Dakr denincedar \\
\hline Wondextm & lonere & 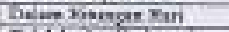 \\
\hline Lmsar & stivg & 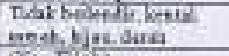 \\
\hline salserala & Bachn & (2) Tม⿰习习) \\
\hline Drisrie: & wora & in $t(2 a)$ \\
\hline Sranchi & nathen & $10 \mathrm{nax}$ \\
\hline Aetranio & Banlen & D) neas \\
\hline Lith & Bamen & $192+203$ \\
\hline Deristimar & Roveres & Ira tices \\
\hline Sunters & Wothen & 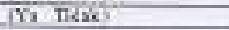 \\
\hline
\end{tabular}

b. Memulai Pencocokan (Case Indexing)

c. Menyeleksi (Case Retrieval)

Pencocokan di mulai dengan memasukan nilai nilai parameter dengan kasus yang di temukan.

2. Reuse

Setelah didapatkan hasil yang serupa maka akan di ambil solusi benupa obat - obatan apa yang disarankan untuk pasien berdasarkan kasus yang telah terjadi.

3. Revise.

Merubah dan mengadopsi solusi yang ditawarkan jika perlu. terdapat dua tugas utama dari tahapan ini yaitu :

1. Evaluasi Solusi.

Evaluasi solusi adalah bagamana hasil yang didapatkan setelah membandingkan solusi dengan keadaan yang sebenarnya. Hal ini biasanya tahapan diluar dari sistim CBR Pada tahap evaluasi ini sering memerlukan waktu yang panjang tergantung dari aplikasi apa yang sedang dikembangkan.

2. Memperbaiki Kesalahan

Perbaikan suatu kasus meliputi pengenalan kesalahan dari solusi yang dibuat dan mengambil atau membuat penjelasan tentang kesalahan tersebut.

4. Retain.

Tetap memakai solusi yang terakhir sebagai bagian dari kasus baru. Pada tahap ini terjadi suatu proses penggabungan dari solusi kasus yang baru yang benar ke knowledge yang telah ads. Terdapat tiga tahapan antara lain : extract, index dan integrate

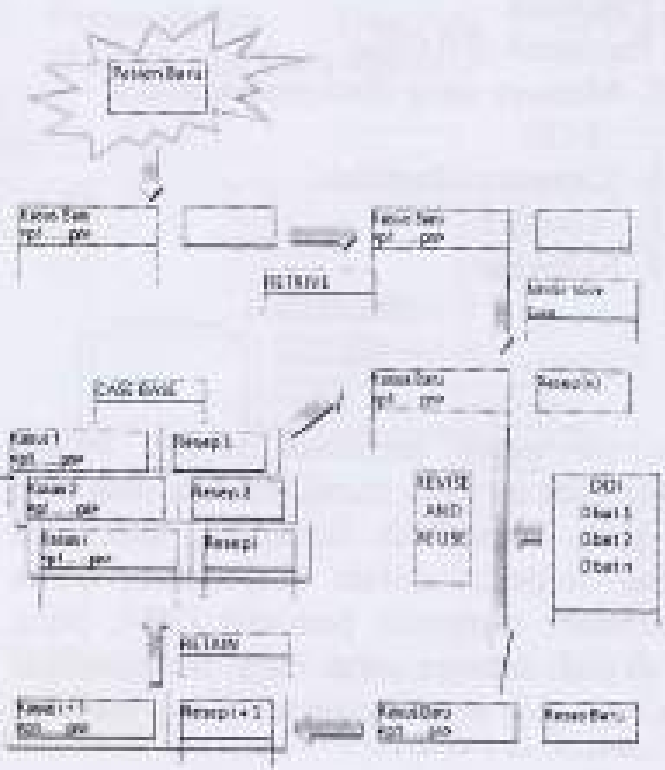

Gambar 5. Rangkaian C BR dalam data obat

\subsection{Analisa Kebutuhan}

Software ini akan di terapkan dan di uji coba ke dokter maupun apotik sebagai penunjang keputusan dalam menentukan resep, adanya admin untuk menginput DOI dani basis pengetahuan dan seorang end user untuk menggunakan mesin CBR tersebut dan menggunakan resep.

Software ini terlebih dahulu akan di isi data DOI dengan parameter yang di tentukan oleh seorang admin, serta admin akan menginput basis pengetahuan yang datanya di dapatkan dari para pakar, jika semua sudah di lakakan barulah end user dapat menginput kasus dari pasien baru untuk mendapatkan resep.

Dalam pengembangan software tersebut bahasa pemrograman Java dengan menggunakan IDE Netbeans dipilih karena mempermudah dalam pembanguna software karena berbasis GUl, Beberapa software di atas membutuhkan spesifikasi hardware yang cukup besar agar kinerja dan kemampuannya menjadi sesuai yang diharapkan

Berdasarkan analisa kebutuhan maka kebutuhan akan sistem yang minimum adalah sebagai berikut:

1. Sistem Operasi Windows: Windows XP propesional 
2. Processor:

Pentium $4,3.0 \mathrm{GHz}$

3. Memory yang direkomendasikan: 2 GB

4. Kapasitas Harddisk: $160 \mathrm{~GB}$

5. Software:

\section{Netbeans 6.8 \\ 2. MySql}

Selain itu untuk membuat sebuah sistem penentu obat ini juga membutuhkan data data obat yang beredar di Indonesia, data data tersebut terdapat dalam DOI serta basis pengetahuan mengenai penyakit ISPA, yang akan di olah datanya untuk dapat memprediksi resep serta obat obatan yang tepat bagi pasien.

\section{UML Diagram}

\subsection{Perancangan Use Case Diagram}

Diagram Use case di sini dijabarkan secara grafis dengan menggambarkan interaksi antara sistem dan pengguna. Diagram Use case berikut menggambarkan seorang user dan admin sebagai penguna yang akan menggunakan sistem CBR untuk menentukan obat yang tepat bagi pasien sekaligus menggambarkan bagaimana cara pengguna berinteraksi dengan sistem yang dibangun.

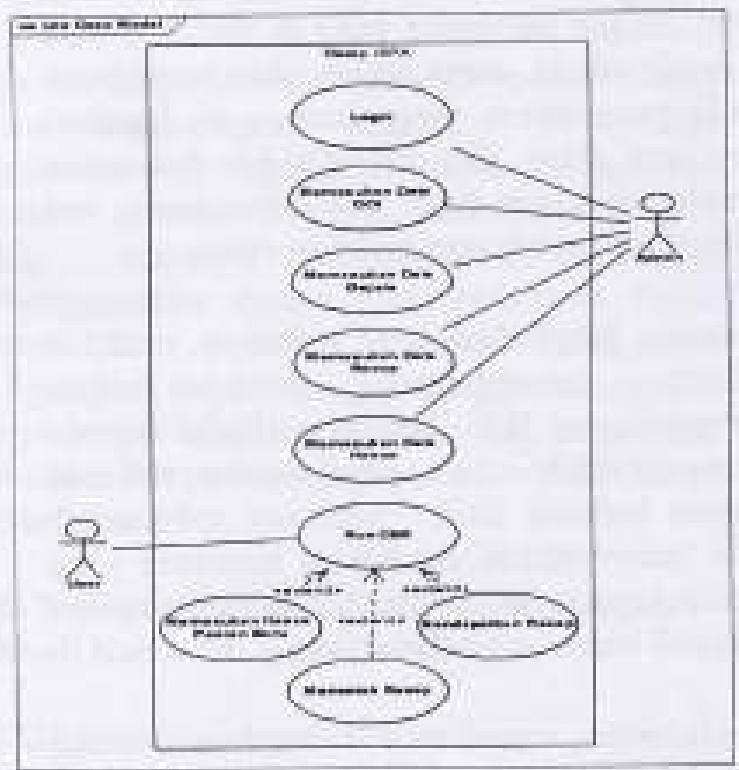

Gambar 6. Use Cave Diagram

\subsection{Perancangan Sequence Diagram}

Diagram Sequence menggambarkan interaksi antar objek di dalam dan di sekitar sistem (termasak pengguna, display, dan sebagainya) berupa message yang digambarkan terhadap waktu. Sequence diagram terdiri atar dimensi vertikal (waktu) dan dimensi horizontal (objekobjek yang terkait).

\section{a. Perancangan Diagram Sequence Login}

Diagram berikut menggambarkan beberapa kelas yang terlibat pada kegiatan login, ada login form, cek hak akses, user, dan menu for.

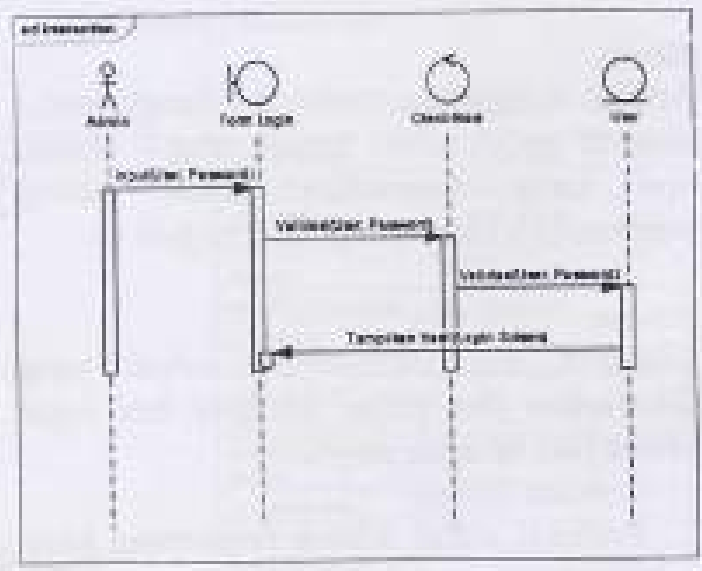

Gambar 7. Sequence Diagran Admin Login

b. Perancangan Diagram Sequence Alses Data DOI 


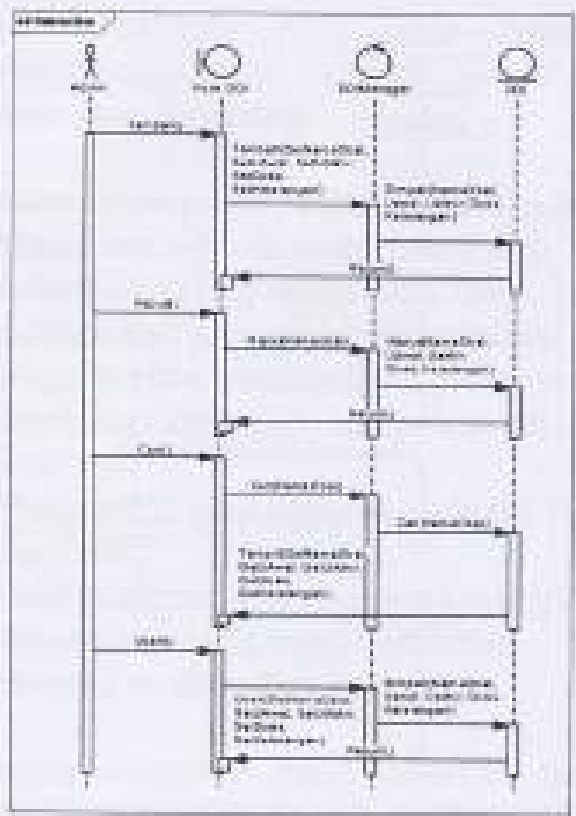

Gambar \&. Sequence Diognam Akses Data DO? d. Perancangan Dlagram Sequence Memasukan Data Kasus

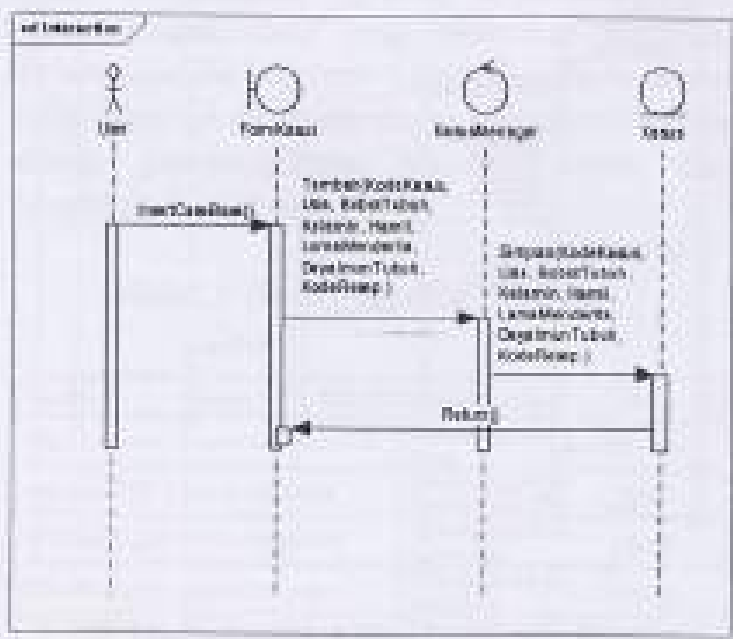

Gambar 60 Masuhan Bü̈а Kasus c. Perancangan Diagram Sequence Memasukan Data Gejala

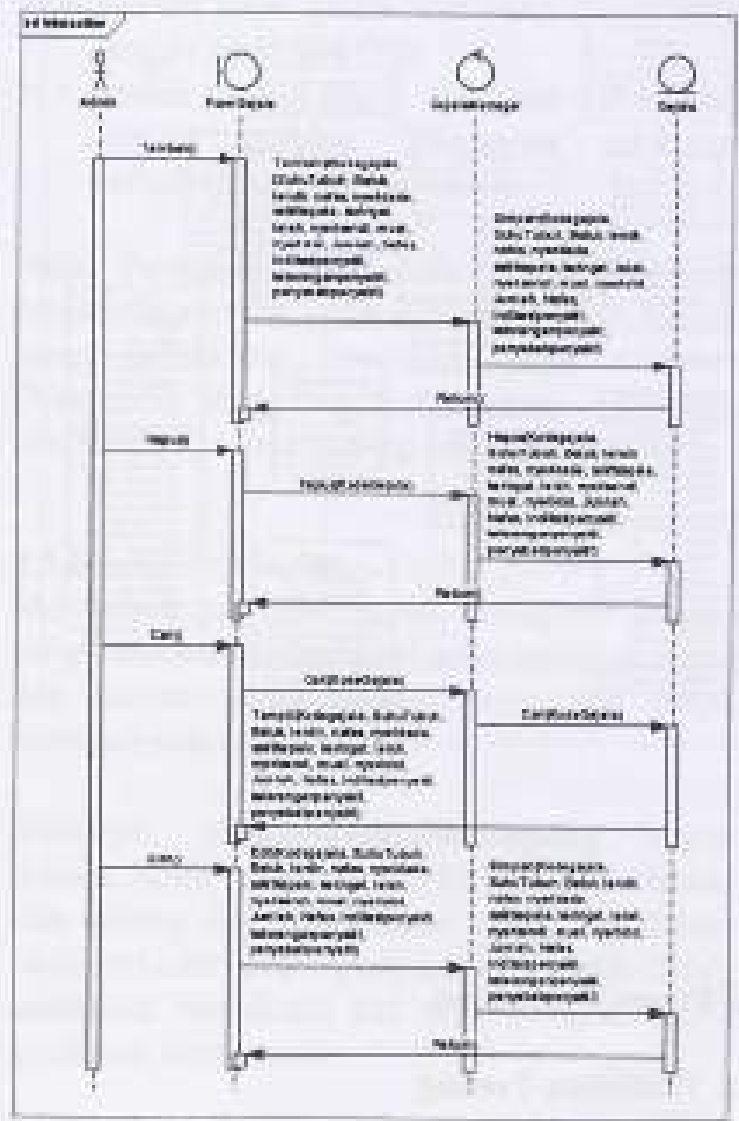

Gambar 9.5 Memasukas Data Gejala e. Perancangan Diagram Sequence Memasukan Data Resep

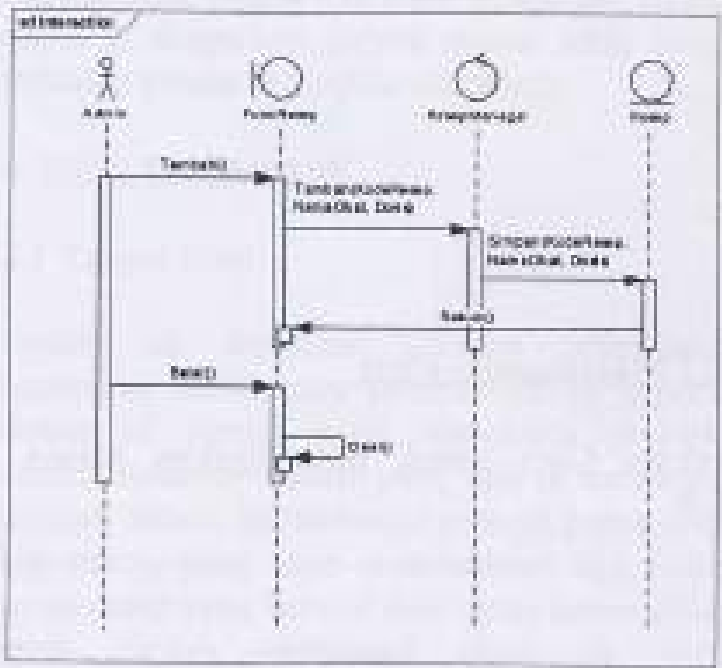

Gambar 71. Akses Daua CbResip

\section{f. Perancangan Diagram Sequence Menjalankan CBR}




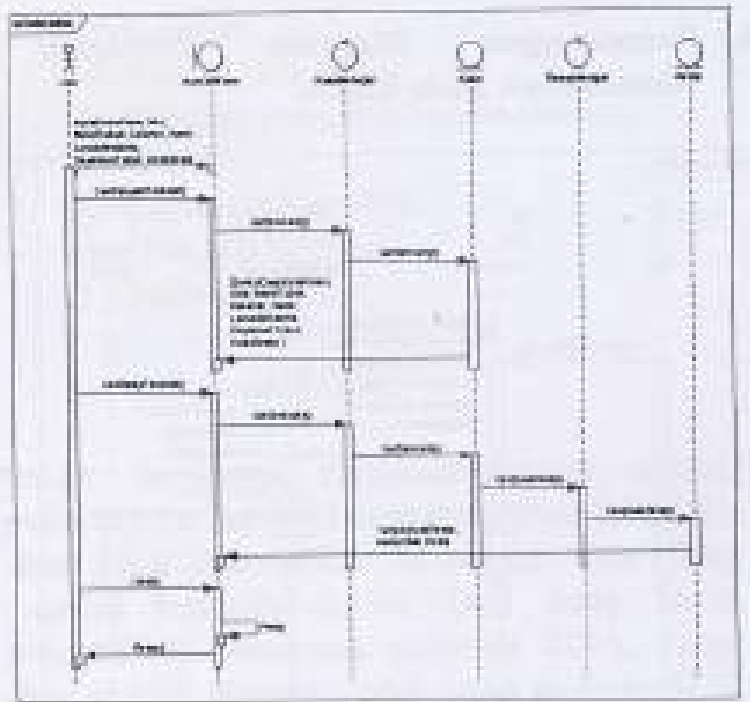

Gambar 8. Segaence Diegram Menjalankan CBR

\subsubsection{Menjalankan CBR}

Diakses User untuk menjalankan Mesin CBR

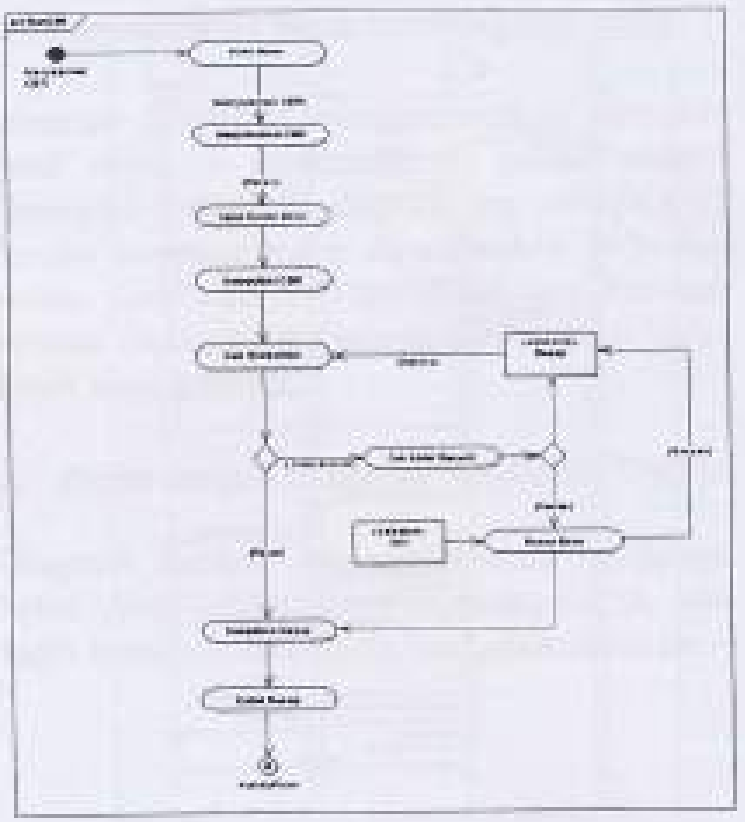

Gambar 13. Acsivity Diagram Menjalankan CBR

\subsection{Perancangan Class Diagram}

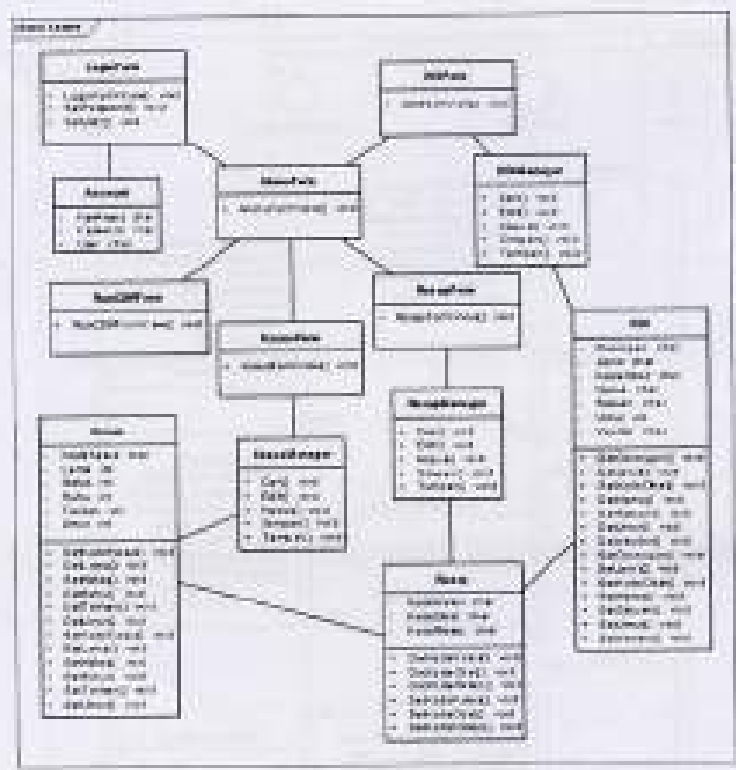

Gambar 10. Class Dlagram

\section{Pengujian Sistem}

\subsection{Whitebox Testing}

Merupakan metode untuk mengetahui cara kerja suatu perangkat lunak secara internal serta meniamin operasi-operasi intemal sesuai 
dengan spesifikasi yang telah ditetapkan dengan menggunakan struktur kendali dari prosedur yang dirancang.

Pelaksanaan pengujian white box antara lain:

1. Menjamim seluruh independent path dicksekusi paling sedikit satu kali. Independent path adalah jalur dalam program yang menunjukkan paling sedikit satu kumpulan proses ataupun kondisi baru.

2. Menjalani logical decision pada sisi true dan false

3. Mengeksekusi pengulangan (looping) dalam batas-batas yang ditentukan

4. Menguji struktur data internal

Pengujian whitebox dapat dilaukan dengan melakukan pengukuran Kompleksitas Siklomatis, yaitu pengukuran kuantitatif terhadap kompleksitas logis dari grafik alir suatu program, menggunakan formula

Dimana:

$$
V(G)=E-N+2
$$

$\mathrm{E}=$ Jumlah edge grafik ahir yang ditandakan dengan gambar panah

$\mathrm{N}$ = Jumlah simpul grafik alir yang ditandakan dengan gambar lingkaran sehingga kompleksitas siklomatisnya

Pada Pengujian Whitebox Testing sistem pemeringkatan ini akan dilakukan pada modul yang melakukan pencarian jarak terdekat (Nearesi) dari sampel yang dihitung similaritasnya dari masing-mnsing indikator.

\subsection{Blackbox Testing}

Merupakan metode untuk menguji fungsifungsi khusus dari aplikasi serta menguji input dan output untuk fungsi yang ada tanpa memperhatikan prosesnya.

Beberapa jenis kesalahan yang dapat diidentifikasi antara lain : Fungsi tidak benat atau hilang, kesalahan antar muka, kesalahan pada struktur data (pengaksesan basis data), kesalahan inisialisasi dan akhir program serta kesalahan performasi.

Metode blackbox adalah pengujian user interface dimana seteiah sistem pemeringkatan perguruan tinggi dipublikasikan harus dapat dipastikan sistem beroprasikan sesuai dengan rancangan. Metode pengujian ini diterapkan untuk memastikan opakah sistem berjalan sesuai dengan event yang diberikan terhadap sistem, apabila keluaran yang dihasilkan sesuai yang diharapkan maka dapat dikatakan bahwa sistem pemeringkatan tersebut lolos dari pengujian blackbox.

Tabel 5. Hasil Pengnjian Blackbox

\begin{tabular}{|c|c|c|c|}
\hline 1eratros & Fisin: & Auper Nist reite & Hed \\
\hline 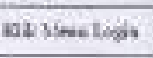 & 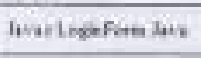 & $\begin{array}{l}\text { Shanciling fint } \\
\text { isge }\end{array}$ & Senni \\
\hline Nat Sientsex & Murbes Mut & 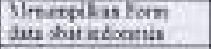 & Senut \\
\hline EkNinucali & lwactiviletore & 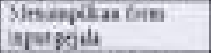 & Srrmi \\
\hline 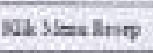 & lytat have fora & 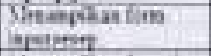 & Strai \\
\hline 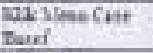 & thaefonctardina & 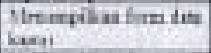 & Senai \\
\hline 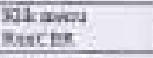 & 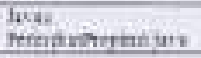 & 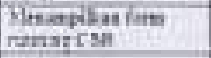 & seren \\
\hline satslensin & Anemen & Solan berme & Sosui \\
\hline 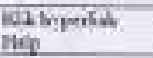 & lovatbeltina & $\begin{array}{l}\text { Somponinatirn } \\
\mathrm{Hilp} \text {. }\end{array}$ & Serrai \\
\hline
\end{tabular}

Pengujian ini dilakukan terhadap seluruh modul yang ada yang hasilnya sesuai dengan rancangan. Pada pengujian ini dilakukan juga pengujian terhadap input, proses dan output. Berdasarkan output dan hasil pengujian, maka dapat di simpulkan bahwa sistem telah lolos terhadap proses pengujian Blackbox.

\section{IMPLEMENTASI}

\subsection{Target User}

Sistem ini ditujukan sebagai penunjang keputusan untuk para penentu resep. seperti dokter di rumah sakit, membuka praktek sendiri maupun mantri yang ada di beberapa tempat. Sistem ini berfungsi sebagai penunjang keputusan, yang akan memberikan tiga buah saran resep yang berasal dari kasus kasus yang telah terjadi, sehingga akan di cari kedekatannya dengan kasus yang ada

Target user terutama sekali di tujukan untuk mantri, maupun dokte umum yang mereka tidak mempelajari secara mendalam suatu penyakit tertentu misalkan saluran pernafasan, sehingga di harapkan software ini dapat menjadi rujukan sebagai sebuah alternatif keputusan untuk menentukan resep yang tepat. 


\subsection{Waktu}

Waktu implementasi sistem dilakukan setelah sistem dan software selesai di buat.

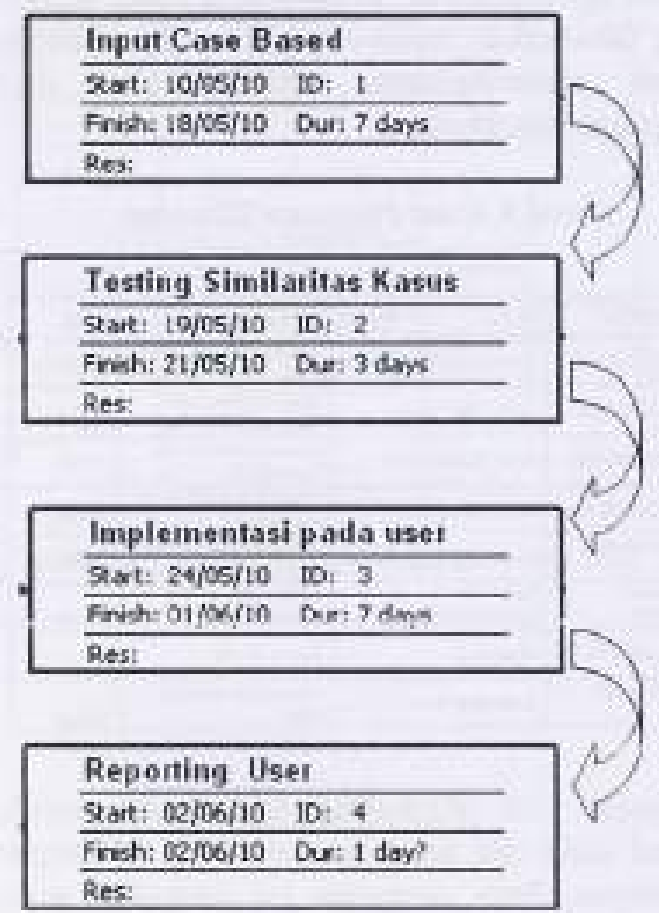

\subsection{Strategi Implementasikan}

Dalam mengimplementasikan sistem ini ada beberapa tahap yang di lakukan untuk memnstikan apakah software dan sistem ini dapat di pakai, tahapan tersebut sebagai berikut

1. Penginputan Case Based berdasarkan resep dari dokter spesialis, atau bahkan penginputan case Basedd dilakukan oleh dokter spesialis itu sendiri.

2. Testing software untuk dicari apakah saran yang di suguhkan sebagai hasil akhir penelitian ini sudah sesuai dengan intuisi para pakar.

3. Implementasi dilakukan pada mantri atau dokter setempat apahila software manpun basis pengetahuan sudah dapat dipertanggung jawabkan.

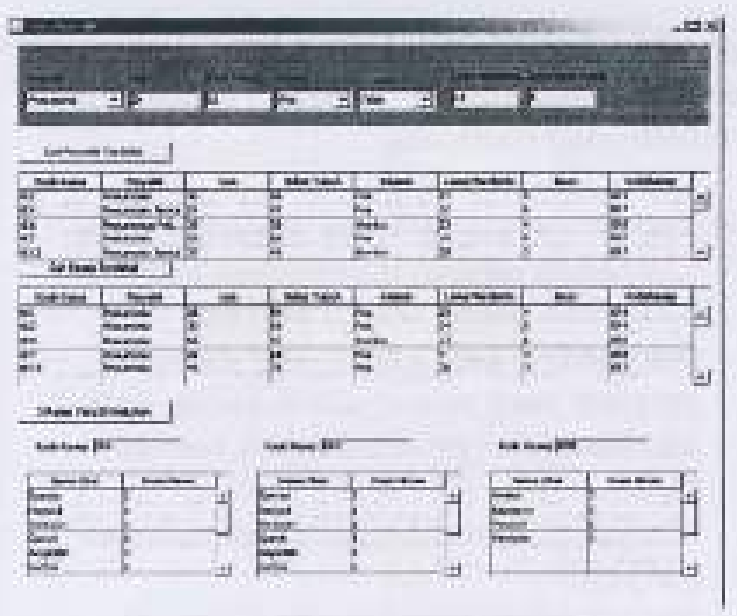

Gambar 11. Printout Hasil CBR

\section{SIMPILAN DAN SARAN}

\subsection{Simpulan}

Berdasarkan hasil penelitian, yang dimulai dan tahap perancangan hingga pengujian Sistem Pemeringkatan dengan mengimplemtasikan Metodologi Case-Basedd Reasaning maka dapat diambil kesimpulan:

1. Implementasi Meodologi Cased-Based Reascning dapat diterapkan untuk menentukan obat dalam hal ini di terapkan pada penyakit ISPA.

2. Kriteria kriteria diterapkan dapat digunakan untuk menentukan obat ISPA sebagai standard pemilihan obat.

\subsection{Saran}

Dari hasil penelitian dan pembahasan terhadap Implementasi Metode Case-Basedd Reasoning Pada Pemeringkatan Perguruan tinggi maka saran yang diusulkan adalah sebagai berikut:

1. Penerapan Case Basedd Reasoning dapat di kembangkan untuk penyakit lainnya, cukup dengan mengganti gejala dan kriteria yang berkaitan dengan penyakit tersebut

2. Sistem Penunjang Keputusan ini dapat di kembangkan dalam media situs, sehingga para pengambil keputusan dapat berinteraksi secara online. 


\section{DAFTAR PUSTAKA}

Aamolt, E. P. (1994). A. Aamadt, E. Plaza (1994): Case-Basedd Reasoning: Foundational Issuex, Methodological Variations, and System Approches. Catalonia, Spain: Al Communications. IOS Press.

Grudic, G. (2004). Nearest Neighbor Learning. Notes borrowed from Thomas G. Dietterich and Tom Mitchell.
Hoffer, J. A. (2006), Modern DataBased Management Dayton: Pearson International Edition.

Mantras, R. L, (2005). Retrieval, Reuse, Revision, and Retention in CaseBasedd Reasaning. United Kingdom: Cambridge University Press DOI.

Siu, S. K. (2004). Fondalions of Soff CaseBasedd Reasoning Canada: Published by John Wiley \& Sons, Inc., Hoboken, New Jersey. 
